\title{
A study on features and functions of family which are relevant to health behavior affecting family health of selected rural population in Bogura district
}

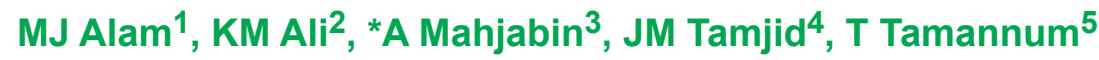

\begin{abstract}
A descriptive type of Cross Sectional study was conducted in two villages named Joyvoga and Chokvochia of Gabtoli upazila, Bogra with a view to finding out the certain features and functions of family which are relevant to health behavior of selected rural population of Bogura district during the period of 20th and 23rd April 2015. Total 278 families were selected purposively. The respondents were aged 15 years and above and the data were collected through open ended pretested questionnaire by face to face interview. Out of 278 respondents, it was found that majority $121(43.52 \%)$ of the respondents were within 31-45 years age group followed by $79(28.41 \%)$ within the age group 15-30 years. Most of the respondents were females 165 (59.32\%), agricultural workers 78 (28.05\%), Muslims $276(99.28 \%)$ \& one- third of the respondents completed their primary education $78(28.06 \%)$. It was found that majority of the families are nuclear $193(69.42 \%)$. Regarding housing condition, majority had satisfactory ventilation status $(84.17 \%)$, safe water using $(93.17 \%)$, using of sanitary latrine $(87.05 \%)$, satisfactory cleanliness (38.12\%) \& domestic waste disposal $25.18 \%$. In case of child (under five) rearing majority were average in weight $(88.85 \%)$ followed by underweight (7.91\%), clean clothing condition (41.01\%). Regarding socialization, attending social clubs $22.3 \%$, schooling $78.42 \%$, attending mosque $84.06 \%$ and taking part in games $87.77 \%$. In case of personality formation most of the respondents can cope with the stress on an average $60.43 \%$ \& had good relation with children $(73.55 \%)$. In relation to care of the dependent adults most $82.56 \%$ of the chronically sick persons did not get proper care, majority $(85.77 \%)$ got satisfactory care during pregnancy. In relation to family condition most of the families are problem family $(90.2 \%)$ followed by peaceful family $(9.73 \%)$. Regarding stress related diseases, majority suffered from hypertension (25.30\%) followed by Peptic Ulcer Disease (24.10\%). This study will help to early detection of health related wrong behavior \& maintenance of family norm can prevent further breakdown of diseases related to family health of the rural people.
\end{abstract}

Keywords: Family type, Housing status, Sanitation, Waste disposal, Child rearing, Bangladesh.

1. Professor Dr. Md. Jahangir Alam, Department of Community Medicine (Ex.), Shaheed Ziaur Rahman Medical College, Bogura.

2. Dr. Khondoker Mohammad Ali, Associate Professor, Department of Community Medicine, Monno Medical College, Manikganj.

3. Dr. Afsana Mahjabin, Assistant Professor, Department of Community Medicine, Monno Medical College, Manikganj. Email: afsana.aqsa@gmail.com

4. Dr. Jarif Mahmud Tamjid, Former Intern Doctor, Shaheed Ziaur Rahman Medical College, Bogura.

5. Dr. Tajkeya Tamannum, Former Intern Doctor, Shaheed Ziaur Rahman Medical College, Bogura. 


\section{Introduction}

Family is a group of biologically related individuals living together and eating from a common kitchen. ${ }^{1} \mathrm{~A}$ family may be nuclear consisting of parents and their children or extened when a large group of relatives live together or in close contact with each other. ${ }^{2}$ There may be other type of family that is broken family or problem family. In fact broken family is a problem family. ${ }^{3}$ Previously family was referred to extended family. Now a days family refers to nuclear family and existence of extended family is very rare in Bangladesh. ${ }^{4}$ Family plays vital role in reproduction, child rearing, education, economic support, support of the dependents and socialization. A peaceful family can perform these activities smoothly but a broken or problem family can result many health problems. For proper functioning of family, healthful housing, waste management and sanitation is needed. But only $56 \%$ of the population was estimated to have access to adequate sanitation facilities in $2010 .{ }^{5}$ Again, a significant percentage of the population has zero access to proper waste disposal service which will in effect lead to the problem of waste management. ${ }^{6}$ This in turn causes many diseases. Poor sanitation has serious consequences for health of the residents and report suggests that most of the child mortality could be related with diseases. ${ }^{7}$ Therefore this study will explore the different aspects \& family functions and its effect on human behavior and occurrence of diseases.

\section{Materials and methods}

This cross sectional descriptive type of study was conducted during the period from 20th to 23rd April 2015 among purposively selected 278 people aged 15 years and above in two villages named Joyvoga and Chokvochia of Gabtoli, Bogura. The Data were collected through pretested open ended questionnaire by face to face interview to find out the certain features and functions of family which are relevant to health behavior. The data thus collected were checked \& verified for any omission \& inconsistency. Finally data were analyzed by SPSS program \& necessary significant tests were done. Then data were presented by necessary tables \& charts.

\section{Results \& Discussion}

Table 01: Socio-demographic characteristics of respondents $(n=278)$

\begin{tabular}{lll}
\hline Characteristics & $\mathbf{n}$ & $\%$ \\
\hline Age of the respondents & & \\
15-30 years & 79 & 28.41 \\
31-45 years & 121 & 43.52 \\
46-60 years & 58 & 20.86 \\
>60 years & 20 & 7.21 \\
Sex of the respondents & & \\
Male & 113 & 40.68 \\
Female & 165 & 59.32 \\
Religion of the respondents & & \\
Islam & 256 & 92.08 \\
Hinduism & 22 & 07.92 \\
Educational status of the & & \\
respondents & & \\
Illiterate & 80 & 28.77 \\
Primary & 78 & 28.06 \\
Secondary & 75 & 26.98 \\
Higher Secondary and above & 45 & 16.19 \\
Occupation of the respondents & & \\
Housewife & 54 & 19.42 \\
Service holder & 35 & 12.59 \\
Agriculture & 78 & 28.05 \\
Business & 45 & 16.18 \\
Day labourer & 36 & 12.95 \\
Others & 30 & 10.81 \\
\hline & &
\end{tabular}

The table shows that majority $121(43.52 \%)$ of the respondents were within 31-45 years age group followed by 79 (28.41\%) within the age group 15-30 years. Most of the respondents were females 165 (59.32\%), Muslims 276 (99.28\%), agricultural workers $78(28.05 \%) \&$ one- third of the respondents completed their primary education 78 (28.06\%). 


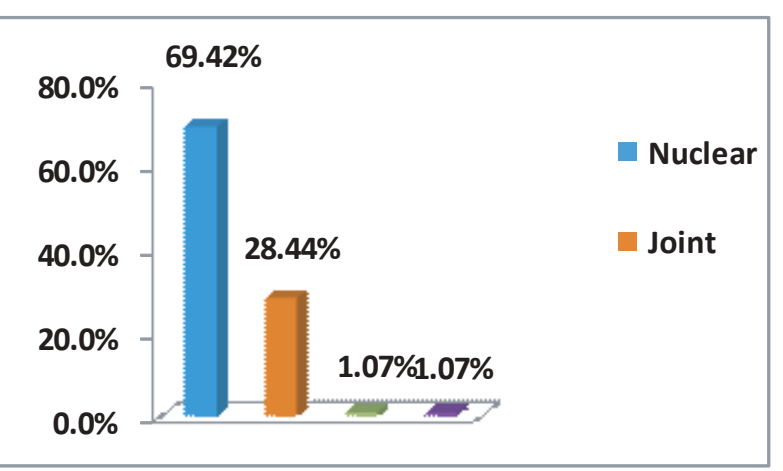

Figure 01: Distribution of respondents according to their family type $(n=278)$

This figure shows that, out of 278 respondents, $193(69.42 \%)$ live in nuclear family followed by $79(28.41 \%)$ joint family, 3 $(1.07 \%)$ blended, $3(1.07 \%)$ one parent families. Another study conducted in rural area of Bangladesh by khan NRI, et al showed that $185(69.8 \%)$ lived in a nuclear family, 69 $(26 \%)$ respondents lived in a joint family and only $11(4.2 \%)$ respondents lived in an extended family which are consistent to this study. 8 This indicates that the old tradition of joint/extended family in our country is decreasing with the emergence of nuclear family as elsewhere in the world.

Table 02: Distribution of respondents according to their housing status $(n=278)$

\begin{tabular}{lcc}
\hline Types & $\mathbf{n}$ & $\mathbf{\%}$ \\
\hline Cleanliness & 106 & 38.13 \\
Satisfactory & 152 & 54.68 \\
Average & 20 & 7.19 \\
Not satisfactory & & \\
Ventilation & 234 & 84.17 \\
Satisfactory & 44 & 15.83 \\
Not satisfactory & & \\
Water supply & 259 & 93.17 \\
Safe & 19 & 6.83 \\
Not Safe & & \\
Sanitary Latrine & 242 & 87.05 \\
Yes & 36 & 12.95 \\
No & & \\
Waste disposal & 70 & 25.18 \\
Satisfactory & 174 & 62.59 \\
Average & 34 & 12.23 \\
Not satisfactory & & \\
\hline
\end{tabular}

This table shows that, more than half of the respondents had average clean house 152 (54.68\%). Out of 278 respondents, ventilation of $234(84.17 \%)$ is satisfactory, $259(93.17 \%)$ people use safe water, $242(87.05 \%)$ people use sanitary latrine and the domestic waste disposal of 174 (25.18\%) people is average. According to some sources, in Bangladesh (2015), sanitation coverage was $61 \%$ which is inconsistent with the result of this study.9, 10 As per Banglapedia, $90 \%$ of the people have access to safe drinking water which is almost same with the result of this study. ${ }^{6}$

Table 03: Distribution of the respondents according to child rearing $(n=272)$

\begin{tabular}{lcc}
\hline Attributes & $\mathbf{n}$ & $\mathbf{\%}$ \\
\hline $\begin{array}{l}\text { Body built (According } \\
\text { to standard } \\
\text { measurements of BMI) }\end{array}$ & & \\
$\begin{array}{l}\text { Underweight } \\
\text { Average }\end{array}$ & 22 & 8.10 \\
Overweight & 247 & 90.80 \\
Clothing & 3 & 01.10 \\
Well & & \\
Poor & 95 & 34.91 \\
Clean & 57 & 20.96 \\
Not clean & 114 & 41.91 \\
\hline
\end{tabular}

This table shows that, out of 278 respondents, body build of $247(90.80 \%)$ is average, $22(8.10 \%)$ is under weight and $3(1.10 \%)$ is overweight. Clothing of $114(41.91 \%)$ is clean, $95(34.91 \%)$ is well, $57(20.96 \%)$ is poor and $6(2.21 \%)$ is not clean. Another study which was held in South Africa conducted by Danae Koetaan et al showed that the prevalence of underweight was $7.7 \%$ which is consistent with this study ${ }^{11}$ \& another study which was conducted in Bangladesh showed that prevalence of underweight was $32.6 \%$ that is inconsistent. ${ }^{12}$ 
Table 04: Distribution of the respondents according to socialization $(n=278)$

\begin{tabular}{lcc}
\hline Traits & $\mathbf{n}$ & $\%$ \\
\hline Schooling & & \\
Yes & 220 & 79.13 \\
no & 58 & 20.86 \\
Attend Social Clubs & & \\
Yes & 62 & 22.30 \\
No & 216 & 77.70 \\
Attend Mosque & & \\
Yes & 234 & 84.17 \\
No & 44 & 15.83 \\
Take part in games & & \\
Yes & 246 & 88.48 \\
No & 32 & 11.51 \\
\hline
\end{tabular}

This table shows that, out of 278 respondents the number of school going person is 220 $(79.13 \%)$, the number of person who attend club is $62(22.30 \%)$, the number of person who attend mosque is $234(84.17 \%)$ and participation in game is 246 (88.48\%). According to the Annual Primary School Census 2017, the dropout rate in the primary education is $18.8 \%$ which is almost same with the result of this study. ${ }^{13}$

Table 05: Personality formation to develop the capacity to withstand stress $(n=278)$

\begin{tabular}{lcc}
\hline Conditions & $\mathbf{n}$ & $\mathbf{\%}$ \\
\hline Coping with stress (effect & on daily & life) \\
Easily cope & 89 & 32.01 \\
Easily upset & 21 & 7.55 \\
Average & 168 & 60.44 \\
Relation with children & & \\
Good & 205 & 73.74 \\
Average & 70 & 25.36 \\
Poor & 03 & 1.09 \\
\hline
\end{tabular}

This table shows that, out of 278 respondents, regarding personality formation, 168 $(60.44 \%)$ people can cope with stress on an average followed by 89 (32.01\%) easily cope and $21(7.55 \%)$ easily become upset. Relation with children of $205(73.74 \%)$ is good, 70 $(25.18 \%)$ is average and $3(1.08 \%)$ is poor.

Table 06: Distribution of the respondents according to the care of dependent adult ( $n=278)$

\begin{tabular}{|c|c|c|}
\hline Trait & $\mathrm{n}$ & $\%$ \\
\hline \multicolumn{3}{|c|}{ Chronically sick person } \\
\hline yes & 49 & 17.63 \\
\hline No & 229 & 82.37 \\
\hline \multicolumn{3}{|c|}{ Care during pregnancy } \\
\hline Satisfactory & 239 & 85.77 \\
\hline Not satisfactory & 39 & 14.23 \\
\hline \multicolumn{3}{|c|}{ Care above 60 years $(n=132)$} \\
\hline Well & 106 & 80.30 \\
\hline Poor & 26 & 19.70 \\
\hline \multicolumn{3}{|c|}{ Care of the handicapped $(n=37)$} \\
\hline Well & 28 & 75.68 \\
\hline Poor & 09 & 24.32 \\
\hline
\end{tabular}

This table shows that out of 278 respondents, taking care of $49(17.63 \%)$ chronically sick person and $239(85.77 \%)$ during pregnancy is satisfactory. Out of 132 respondents, care above 60 years old person is well $106(80.30 \%)$ and $26(19.70 \%)$ is poor. $A$ stuies held in rural area of Bangladesh conducted by F. Mahejabin et al showed that $76.8 \%$ of the respondents received antenatal services which is more or less same with this study. ${ }^{14}$ Another study conducted by Farah S, et al showed that $63.4 \%$ of the respondents received antenatal services which is similar to this study. ${ }^{15}$ Out of 37 respondents, care of the handicapped is well in $28(75.68 \%)$ and poor in $09(24.32 \%)$ families. 
Table No. 07 Distribution of the respondents according to family condition $(n=278)$

\begin{tabular}{lcc}
\hline Traits & $\mathbf{n}$ & $\%$ \\
\hline Broken family & & \\
Parents separated & 8 & 2.87 \\
Parent/s deceased & 13 & 4.67 \\
Problem family & & \\
Poverty & 98 & 35.26 \\
Severe chronic Illness & 108 & 38.84 \\
Emotional instability & 21 & 7.55 \\
Character defect & 3 & 1.08 \\
Others (Peaceful family) & 27 & 9.73 \\
\hline
\end{tabular}

This table shows that, out of 278 respondents, the number of parent separated broken family is $8(2.87 \%)$ and the number of parent death broken family is $13(4.67 \%)$ This table also shows that, 108 (38.84\%) families have severe chronic illness, 98 (35.26\%) families are suffering from poverty, 21 $(7.55 \%)$ families have emotional instability and $3(1.08 \%)$ families have character defect.

Table 08: Distribution of the respondents according to stress related diseases $(n=278)$

\begin{tabular}{lcc}
\hline Types & $\mathbf{n}$ & $\mathbf{\%}$ \\
\hline Peptic Ulcer disease & 67 & 24.10 \\
Hypertension & 72 & 25.30 \\
Bronchial Asthma & 42 & 15.11 \\
Rheumatism & 20 & 7.19 \\
Drug addiction & 5 & 1.80 \\
Alcoholism & 1 & 0.03 \\
\hline
\end{tabular}

This table shows that, out of 278 respondents, $72(25.30 \%)$ people are suffering from hypertension, followed by $67(24.10 \%)$ peptic ulcer disease, 42 (15.11\%) bronchial asthma, $20(7.19 \%)$ rheumatism, $5(1.80 \%)$ drug addiction and 1 (0.03\%) alcoholism. According to BBS (2017), the prevalence of hypertension \& bronchial asthma were $5.45 \%$ and $2.33 \%$ respectively which are inconsistent with the result of this study.10 A study held in Manikganj conducted by Alam, M.J., et al revealed that prevalence of hypertension \& bronchial asthma were $7.7 \%$ and $0.7 \%$ respectively which are quite different with the findings of this study. ${ }^{16}$

\section{Conclusion}

Family is a fundamental social unit. It is the main place for health development, education, personality \& social development of the people. Occurrence of many diseases is also related directly or indirectly with healthful family environment, housing condition, sanitation \& waste disposal. Therefore, the result of this study will help the concerned authority to take necessary steps to improve the health of the families of rural people of Bangladesh.

\section{References}

1. PARK K. Medicine and Social Sciences. Park's Textbook of Preventive and Social Medicine. 24th edition. 1167 Prem Nagor,Nagpur Rd,Jabalpur(India): M/S Banarsidas Bhanot; 2017. p. 719.

2. Banglapedia, National encyclopedia of Bangladesh. [Internet]. Asiatic society of Bangladesh: 2014. Available from: https://www.banglapedia.org/. [Accessed on 2019 July 24].

3. AH Suryakantha. Social Science. Community Medicine with Recent Advances.4th edition. New Delhi: The Health science publisher; 2017. p. 740.

4. Rizvi MR. Why extended family breaking down in Bangladesh. [Internet]. Daily Sun:2018. Available from: https:// www.daily-sun.com/ printversion/ details/ 339513/2018/09/30/Why-extendedfamily-breaking-down-in-Bangladesh. [Accessed on 2019 July 24].

5. Water supply and sanitation in Bangladesh. [Internet]. Wikipedia :2012. Available from: https:// en.wikipedia.org/ wiki/ 
Water_supply_and_sanitation_in_Bangla desh. [Accessed on 2019 July 14].

6. Alamgir M, Ahsan A. Municipal Solid Waste and Recovery Potential: Bangladesh Perspective. Iran J Environ Health Sci Eng. 2007; 4(2): 67-76.

7. Memon MA. Solid Waste Management in Dhaka, Bangladesh. [Internet]. Innovation in Community driven Composting: 2002. Available from: https://kitakyushu.iges. or.jp/docs/demo/dhaka_bangladesh/spdh aka.pdf. [Accessed on 2019 July 14].

8. Khan NR, Jerifa S. Prevalence of contraceptive use among married women of reproductive age groups in a rural area of bangladesh. J Dhaka Med Coll. 2014 April;23(1):7-13 .

9. Water supply and sanitation in Bangladesh. [Internet]. Wikipedia :2015. Available from: https://en.wikipedia. org/wiki/ Water_supply_and_sanitation_in_Bangla desh. [Accessed on 2019 July 17]

10. Statistical pocket Book Bangladesh, Bangladesh Bureau of Statistics (BBS), Statistics \& Informatics Division (SID), Ministry of Planning, 2017, page-103.

11. .Koetaan D, Smith A, Liebenberg A, et al. The prevalence of underweight in children aged 5 years and younger attending primary health care clinics in the Man gaung area, Free State. Afr J Prm Health Care Fam Med. 2018 May 28;10(1): 1476.

12. Bangladesh BD: Prevalence of Underweight: Weight for Age: \% of Children Under 5. [Internet]. World Bank: 19862014. Available from: https:/ /www.ceicdata.com/en/bangladesh/health -statistics/bd-prevalence-of-underweightweight-for-age--of-children-under-5. [Accessed on 2019 July 24].

13. 18.8pc dropout in primary education. [Internet]. United News of Bangladesh: 2018. Available from: http:// www.newagebd.net/ article/ 32556/ article/articlelist/323/article/35972 [Accessed on 2019 July 17].

14. Mahejabin F, Parveen S, Sajani TT. Antenatal Care Practices in Some Selected Rural Areas of Bangladesh. AKMMC J. 2016 March 22; 7(2):06-11.

15. Farah S, Karim M. Determinants of utilization of antenatal care services in rural area of Bangladesh. Bangladesh Med J. 2015 May; 44(2):67-71.

16. Alam MJ, Ali KM, Mahjabin A, Hasan M, Tasrin R, Emdad S, et al. A STUDY ON MENTAL HEALTH STATUS OF THE RURAL PEOPLE IN A SELECTED AREA OF BANGLADESH. Shaheed Ziaur Rahman Med. J. 2019 July (accepted by editorial board of publication). 